\title{
Impact of interspecific interactions on antimicrobial activity among soil bacteria
}

\section{Olaf Tyc ${ }^{1}$, Marlies van den Berg ${ }^{1}$, Saskia Gerards ${ }^{1}$, Johannes A. van Veen ${ }^{1}$, Jos M. Raaijmakers ${ }^{1}$, Wietse de Boer ${ }^{1,2}$ and Paolina Garbeva ${ }^{1 *}$}

${ }^{1}$ Department of Microbial Ecology, Netherlands Institute of Ecology (NIOO-KNAW), Wageningen, Netherlands

${ }^{2}$ Department of Soil Quality, Wageningen University and Research Centre, Wageningen, Netherlands

\section{Edited by:}

Eoin L. Brodie, Lawrence Berkeley

National Laboratory, USA

\section{Reviewed by:}

Trevor Carlos Charles, University of Waterloo, Canada

Alexandre Jousset, Utrecht

University, Netherlands

Matthew F. Traxler, Harvard Medical

School, USA

*Correspondence:

Paolina Garbeva, Department of Microbial Ecology, Netherlands Institute of Ecology (NIOO-KNAW), PO BOX 50, $6700 A B$ Wageningen, Netherlands

e-mail:p.garbeva@nioo.knaw.nl
Certain bacterial species produce antimicrobial compounds only in the presence of a competing species. However, little is known on the frequency of interaction-mediated induction of antibiotic compound production in natural communities of soil bacteria. Here we developed a high-throughput method to screen for the production of antimicrobial activity by monocultures and pair-wise combinations of 146 phylogenetically different bacteria isolated from similar soil habitats. Growth responses of two human pathogenic model organisms, Escherichia coli WA321 and Staphylococcus aureus 533R4, were used to monitor antimicrobial activity. From all isolates, 33\% showed antimicrobial activity only in monoculture and $42 \%$ showed activity only when tested in interactions. More bacterial isolates were active against $S$. aureus than against $E$. coli. The frequency of interaction-mediated induction of antimicrobial activity was 6\% (154 interactions out of 2798) indicating that only a limited set of species combinations showed such activity. The screening revealed also interaction-mediated suppression of antimicrobial activity for $22 \%$ of all combinations tested. Whereas all patterns of antimicrobial activity (non-induced production, induced production and suppression) were seen for various bacterial classes, interaction-mediated induction of antimicrobial activity was more frequent for combinations of Flavobacteria and alpha- Proteobacteria. The results of our study give a first indication on the frequency of interference competitive interactions in natural soil bacterial communities which may forms a basis for selection of bacterial groups that are promising for the discovery of novel, cryptic antibiotics.

Keywords: soil bacteria, inter-specific interactions, high-throughput-screening, antimicrobial activity, antibiotic discovery

\section{INTRODUCTION}

Production of antimicrobial compounds is an important strategy to increase competitiveness of soil bacteria. Soil is a heterogeneous, nutrient-poor and harsh environment harboring a huge diversity of bacteria (Gans et al., 2005; Uroz et al., 2010). There is also considerable functional redundancy as many soil bacterial species can use similar substrates as an energy source for growth and persistence (Yin et al., 2000; Strickland et al., 2009). Therefore, inter-specific competition for nutrient resources is a major type of interaction in soil bacterial communities (Demoling et al., 2007; Rousk and Baath, 2007; Rousk et al., 2009). An important strategy in interspecific interactions, known as interference competition, is the production of growth inhibitory secondary metabolites (e.g., antibiotics, toxins, biosurfactants, volatiles and others) that can suppress or kill microbial opponents (Hibbing et al., 2010; Cornforth and Foster, 2013). Although the production of antimicrobial compounds could inhibit the growth of bacterial strains competing for resources, in some cases the produced antimicrobial compounds could also promote the growth of other bacteria (D'costa et al., 2006; Dantas et al., 2008), act as signaling molecules
(Linares et al., 2006; Romero et al., 2011) or modulate bacterial gene expression in sub inhibitory concentrations (Goh et al., 2002).

Whole genome sequencing has revealed that many soil microorganisms possess so-called cryptic gene clusters encoding for putative new secondary metabolites that are not produced during common in vitro conditions (Ikeda et al., 2003; Scherlach and Hertweck, 2009; Chiang et al., 2011; Saleh et al., 2012). In nature, however, antibiotics may be produced after perception of specific environmental signals (stress/nutrient signals) or signals from neighboring microorganisms (competitor sensing) (Firn and Jones, 2003; Cornforth and Foster, 2013; Zhu, 2014). Indeed, several studies have indicated that antibiotic production in soil bacteria can be induced when they are confronted with other bacterial species (Slattery et al., 2001; Lyon and Muir, 2003; Maurhofer et al., 2004; De Boer et al., 2007b; Seyedsayamdost et al., 2012). We hypothesize that competitor induced (facultative) rather than constitutive antibiotic production represents a key strategy in interference competition that is cost-effective and/or may reduce selection of antibiotic-resistant competitors (Garbeva et al., 2011b). Interaction-mediated induction 
of antibiotic production is also interesting from an applied perspective as it may lead to the discovery of novel antibiotics.

The aim of the current study was to obtain insight in the frequency of interaction-mediated induction of antibiotic production in natural soil bacterial communities. To this end, we screened a collection of bacterial isolates obtained from similar soil habitats. We developed and applied a high-throughput method to screen bacteria for the production of compounds that inhibit growth of Gram-positive and Gram-negative isolates that are closely related to human pathogens. By selecting these target organisms the study not only revealed information on the frequency of interaction-mediated antibiotic production, but also on specific soil bacterial genera or species that could be promising candidates for the discovery of novel antibiotics. The obtained results revealed that interactions have a major impact on antimicrobial compound production albeit with effects in both directions i.e., induction and suppression of antimicrobial activity.

\section{MATERIALS AND METHODS}

\section{SOIL BACTERIA AND CULTURE CONDITIONS}

We selected 146 bacterial isolates from organic-poor, sandy soils under vegetation patches of sand sedge (Carex arenaria L.) growing in natural field sites (De Ridder-Duine et al., 2005) (Table S1). The bacterial isolates were pre-cultured from $-80^{\circ} \mathrm{C}$ glycerol stocks on $1 / 10$ TSBA $\left(5.0 \mathrm{gL}^{-1} \mathrm{NaCl}, 1.0 \mathrm{gL}^{-1} \mathrm{KH}_{2} \mathrm{PO}_{4} ; 3 \mathrm{gL}^{-1}\right.$ Oxoid Tryptic Soy Broth; $20 \mathrm{gL}^{-1}$ Merck Agar, pH 6.5) (Garbeva and De Boer, 2009) and incubated for 5-7 days at $20^{\circ} \mathrm{C}$ prior to screening.

\section{CONTROL STRAINS AND TARGET ORGANISMS}

Reference strains that produce known antibiotics in monoculture were obtained from the DSMZ strain collection (Leibniz Institute DSMZ-German Collection of Microorganisms and Cell Cultures, Braunschweig, Germany). These reference strains were: Streptomyces kanamyceticus (DSM 40500), producer of kanamycin, Streptomyces rimosus (DSM 40260), producer of oxytetracycline and Streptomyces nodosus (DSM 40109) producer of amphotericin A and B. These strains were pre-cultured from $-80^{\circ} \mathrm{C}$ glycerol stocks on GYM agar plates $\left(4.0 \mathrm{gL}^{-1}\right.$ Glucose, $4.0 \mathrm{gL}^{-1}$ BACTO $^{\mathrm{TM}}$ Yeast extract, $10.0 \mathrm{gL}^{-1}$ Malt extract, $2.0 \mathrm{gL}^{-1} \mathrm{CaCO}_{3}, 20 \mathrm{gL}^{-1}$ Merck Agar, $\mathrm{pH}$ 7.2) and incubated for 7 days at $28^{\circ} \mathrm{C}$ before inoculation into 96-well source plates (see below). In the agar-overlay assay, two bacterial strains were selected to act as model organisms for human pathogenic bacteria: Escherichia coli WA321 (DSM 4509) as Gram-negative target organism and Staphylococcus aureus 533R4 Serovar 3 (DSM 20231) as Gram-positive target organism. The target strains were pre-cultured from $-80^{\circ} \mathrm{C}$ glycerol stocks on Luria Bertani (LB) agar plates $\left(10.0 \mathrm{gL}^{-1} \mathrm{NaCl}, 10 \mathrm{gL}^{-1}\right.$ Bacto $^{\mathrm{TM}}$ Tryptone, $5 \mathrm{gL}^{-1}$ Bacto $^{\mathrm{TM}}$ Yeast extract, $20 \mathrm{gL}^{-1}$ Merck Agar) Sambrook and Russell (2001) and incubated at $37^{\circ} \mathrm{C}$ for $24 \mathrm{~h}$ before inoculation in the antimicrobial screening assay. Characteristics of the target and the control strains are listed in Table S3.

\section{PREPARATION OF OMNITRAYTM PLATES}

For the high-throughput interaction assay polystyrene $\mathrm{Nunc}^{\mathrm{TM}}$ OmniTray $^{\mathrm{TM}}$ _plates (size $128 \times 86 \mathrm{~mm}$; cap. $90 \mathrm{~mL}$; $\mathrm{Nunc}^{\mathrm{TM}}$,
Nalge Nunc International, Rochester, NY, USA Cat \# 82-264728) were used. Each OmniTray ${ }^{\mathrm{TM}}$ plate was filled with $45 \mathrm{~mL}$ of $1 / 10$ TSBA $(2 \%)$ agar. Plates were kept in the laminar flow cabinet until the agar was completely solidified.

\section{PREPARATION OF 96-WELL SOURCE-PLATES}

96-well Microtiter plates (Greiner bio-one B.V., Alphen a/d Rijn, The Netherlands, Cat\# 655180) were prepared to inoculate the selected bacterial isolates and the reference strains. Each well was filled with $150 \mu \mathrm{l}$ liquid LB broth. Bacterial isolates were inoculated in 10 rows containing quadruplicates of each strain, the 11th row was kept empty and the 12 th row was used as positive control by inoculating known antibiotic-producing Streptomyces strains in duplicate with one free well between each strain (Figure 1). Inoculation was done by picking cells from a single colony of each bacterial strain with a disposable inoculation loop (VWR international B.V., Amsterdam, The Netherlands Cat\# 50806-404) and transferring to the designated well in the 96-well source plates. The plates were incubated for 2 days at $24^{\circ} \mathrm{C}$, after which the

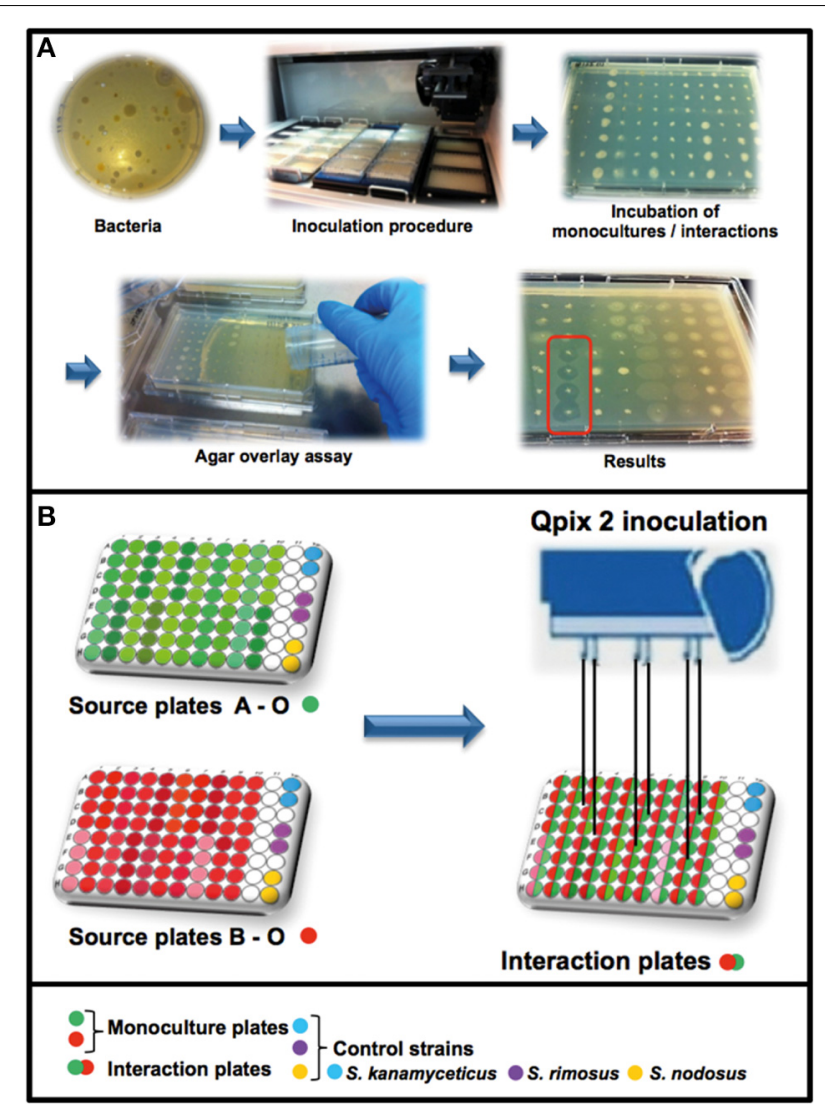

FIGURE 1 | Workflow of the high-throughput interaction assay. (A) Overview of the antimicrobial screening: bacteria were inoculated with a Genetix Opix 2 colony picking robot either in monoculture or in one-to-one interactions on OmniTray ${ }^{\mathrm{TM}}$ plates. For the detection of antimicrobial activity an agar overlay assay with two target organisms was performed on the fourth day of incubation. Antimicrobial activity was determined on the 5 th day after overnight incubation at $37^{\circ} \mathrm{C}$ by screening for visible zones of inhibition (ZOI) in the upper agar layer. (B) Overview of the 96-well plates design and the inoculation procedure using the Genetix QPix2 colony picking robot. 
plates were prepared for long-term storage $\left(-80^{\circ} \mathrm{C}\right.$ freezer $)$ by adding $50 \mu \mathrm{l}$ of $50 \%(\mathrm{v} / \mathrm{v})$ glycerol to achieve a final concentration of $12.5 \%(\mathrm{v} / \mathrm{v})$. In total, 15 Microtiter plates (source plates A-O) containing different compositions of monocultures of bacterial isolates were prepared for the high-throughput interaction assay.

\section{HIGH-THROUGHPUT INTERACTION ASSAY}

A Genetix QPix 2 colony picking robot (Molecular Devices, UK Limited, Wokingham, United Kingdom) was used for the highthroughput interaction assay. The Genetix QPix 2 robot was mounted with a bacterial 96-pin picking head and programmed to replicate the source plates (96-well Microtiter plates) into the $\mathrm{OmniTray}^{\mathrm{TM}}$ plates (Figure 1). The source plates were replicated two times, one set of inoculated plates was removed from the robot and was used as control to estimate growth and antimicrobial activity of the monocultures. The remaining plates in the robot were used for the interaction assay by inoculating a second set of source-plates in various combinations. The second set of bacterial isolates was inoculated at the same position as the first set of bacteria, in this way the bacterial isolates had physical cell contact and could interact in one-to-one interactions (in quadruplicates). The inoculated OmniTray ${ }^{\mathrm{TM}}$ plates (monocultures and interaction plates) were incubated for 4 days at $24^{\circ} \mathrm{C}$. In total, 146 bacterial isolates were combined with each other in various arrangements and tested in 2798 unique interactions for the production of antimicrobial compounds.

\section{ANTIMICROBIAL SCREENING}

For detection of antimicrobial activity, an agar overlay assay was performed on the 4th day of incubation (Nkanga and Hagedorn, 1978). The two target organisms E. coli WA321 and S. aureus 533R 4 were grown overnight in liquid $\mathrm{LB}$ broth at $37^{\circ} \mathrm{C}, 220 \mathrm{rpm}$. Fresh LB- agar (1.5\% Merck Agar) was prepared, cooled down to $\sim 45^{\circ} \mathrm{C}$ and the target organisms were added to a final $\mathrm{OD}_{600}$ of 0.002 corresponding to approximately $6 \times 10^{\wedge} 5 \mathrm{CFU} / \mathrm{mL}$ (E. coli WA321) or $4 \times 10^{\wedge} 5 \mathrm{CFU} / \mathrm{mL}$ (S. aureus $\left.533 \mathrm{R} 4\right)$ and mixed well. A volume of $15 \mathrm{~mL}$ liquid LB-agar containing the target organisms was poured over the OmniTray ${ }^{\mathrm{TM}}$ plates with the empty 11 th row as the start position for pouring. After solidification of the overlay agar, the OmniTray ${ }^{\mathrm{TM}}$ plates were incubated overnight at $37^{\circ} \mathrm{C}$. The next day ( 5 th day), plates were examined for visible zones of inhibition (ZOI). Monocultures or mixed-cultures of the soil bacterial isolates were scored as positive for antibiotic production if at least two out of four replicates produced zones of inhibition (Figure 1A). The majority of activity reported ( $>55 \%$ ) involved $\geq 3$ out of 4 replicates. For confirmation of the high-throughput screening results, several of the antibiotictriggering/suppressing interactions were tested outside the HTS setup (Figures S7, S8).

\section{PCR AND 16S rRNA GENE SEQUENCING}

For identification of the bacterial isolates, PCRs were performed directly on colonies or with extracted genomic DNA. For genomic DNA extraction the QIAGEN QIAmp DNA Mini Kit (QIAGEN Benelux B.V., Venlo, The Netherlands cat\# 51 304) was applied according to the manufacturer's manual. For the colony PCRs, a few colonies of each bacterial isolate were scraped from the plate with a disposable inoculation loop (VWR international B.V., Amsterdam, The Netherlands Cat\# 50806-404) and resuspended in $250 \mu \mathrm{l}$ sterile MQ-water. The re-suspended bacterial cells were pulse vortexed and heated to $95^{\circ} \mathrm{C}$ for $5 \mathrm{~min}$. Tubes were centrifuged for $3 \mathrm{~min}$ at $12,000 \times \mathrm{g}$ and $1 \mu \mathrm{l}$ supernatant from each bacterial isolate was applied in a $50 \mu \mathrm{l}$ PCR- master mix (Promega Corp. Madison, USA cat\# M7505). For 16S rRNA gene amplification, one of the two primer combinations was used: (1) forward primer pA ( $5^{\prime}$ - AGA GTT TGA TCC TGG CTC AG $\left.-3^{\prime}\right)$, reverse primer 1492r $\left(5^{\prime}\right.$ - GRT ACC TTG TTA CGA CTT $-3^{\prime}$ ), amplifying $\sim 1492$ bp from the $16 \mathrm{~S}$ rRNA gene or (2) forward primer 27f (5' - AGA GTTT GAT CMT GGC TCAG $-3^{\prime}$ ), reverse primer $1492 \mathrm{r}$ amplifying $\sim 1465 \mathrm{bp}$ from the $16 \mathrm{~S}$ rRNA gene (Edwards et al., 1989; Lane, 1991) (modified). All PCR reactions were performed on a MJ Research Peltier thermal cycler 200 PCR machine (Harlow Scientific, Arlington, USA) with the following settings: initial cycle $95^{\circ} \mathrm{C}$ for $5 \mathrm{~min}$. and 30 cycles of $94^{\circ} \mathrm{C}$ for $30 \mathrm{sec}$, $55^{\circ} \mathrm{C}$ for $30 \mathrm{sec}$. and $72^{\circ} \mathrm{C}$ for $1 \mathrm{~min}$. After amplification, a volume of $5 \mu$ l of each PCR reaction was loaded on a $1.25 \%(\mathrm{w} / \mathrm{v})$ agarose gel and checked after electrophoresis for presence of PCR fragment. The PCR products were sent to MACROGEN (MACROGEN Europe, Amsterdam, The Netherlands) for sequencing.

\section{PHYLOGENETIC ANALYSIS AND SEOUENCE ANALYSIS}

Obtained sequence chromatograms of the 16S rRNA gene were examined for quality and trimmed to approximately the same size $(\sim 650 \mathrm{bp})$ using 4 PEAKS V1.7.2 for MAC OS X (www.nucleobytes.com) (C2006 Mek\&Tosj.com and Clustal W. The aligned 16S rRNA gene sequences were compared against those available in the NCBI database by BLASTN (blast.ncbi.nlm.nih.gov) (Altschul et al., 1997). The sequences obtained during this study are deposited in NCBI GenBank under accession numbers KJ685218-KJ685361. For two isolates, the 16S rRNA sequences were available from previous work: P. fluorescens (strain AD21): DQ778036, Pedobacter sp. (strain V48): DQ778037 (De Boer et al., 2007a).

\section{NETWORK VISUALIZATION OF INTERACTIONS}

The bacterial interaction pairs that triggered or suppressed antimicrobial activity against the target organisms were visualized with Cytoscape 3.0.2 (www.cytoscape.org) for MAC OS $\mathrm{X}$ (Shannon et al., 2003). Interaction visualizations were performed with the following parameters: each phylogenetic class was visualized as a single node with different symbols for each phylogenetic class, the interactions between the phylogenetic classes (nodes) were visualized by links (edges) connecting each interacting phylogenetic class. Node colors were scaled to the number of interactions between the different phylogenetic classes (see Figure legends). For visualization, self-loops (interactions within the same phylogenetic class) and edges (interactions between phylogenetic classes) were bundled to single links between the respective phylogenetic classes (the darker the line the higher the number of interactions between the phylogenetic classes). 


\section{STATISTICAL ANALYSIS}

Statistical analyses on frequencies for induction and/or suppression of antimicrobial compound production between the different Gram-groups were performed with http://math.hws. edu/javamath/ryan/ChiSquare.html using online chi square tests. Results of the chi-square test are shown in Tables S5, S6.

\section{RESULTS}

\section{PHYLOGENY OF THE TESTED BACTERIAL ISOLATES}

16S rRNA gene sequence analysis revealed that the 146 bacterial isolates tested in this study belonged to 4 phyla covering 7 classes and 9 genera: Proteobacteria (14 alpha-Proteobacteria, 65 beta-Proteobacteria, 29 gamma-Proteobacteria), Bacteroidetes (19 Flavobacteria, 1 Sphingobacteria), Actinobacteria (11 Actinobacteria) and Firmicutes (7 Bacilli) (Table 1 and Table S1).

\section{HIGH-THROUGHPUT SCREENING FOR ANTIMICROBIAL ACTIVITY}

We developed a high-throughput assay to screen for production of antimicrobial compounds by interacting bacteria (Figure 1). In total 146 isolates were screened in monocultures and in 2798 random one-to-one interactions. For 17 isolates (11\%), no activity against $E$. coli and $S$. aureus was detected not in monocultures nor in mixed cultures (Table $S 1$ and Figure 2A). For 20 isolates (14\%) antibacterial activity was observed in both monoculture and mixed cultures. For 48 isolates (33\%), this was restricted to monocultures only and for 61 isolates (42\%) antibacterial activity was only apparent during interactions (Figures 2A, 3). The number of isolates (110) involved in activity against the Gram-positive target strain $S$. aureus 533R4 was more than twice the number of isolates (45) with activity against the Gram-negative target strain E. coli WA321 (Table 1, Table S1). Despite the high number of bacterial isolates involved in antimicrobial activity in interactions, the frequency of interaction-mediated induction of antimicrobial activity was low $\sim 6 \%$ (154 interactions out of 2798). This implies that interaction-mediated induction was only occurring in a limited number of combinations (Tables 2, 3). Most interactions (72\%) did not have an effect on antimicrobial activity (induction or suppression) and about $22 \%$ of the interactions suppressed antimicrobial activity in isolates that revealed activity in monoculture (Figure 2B).

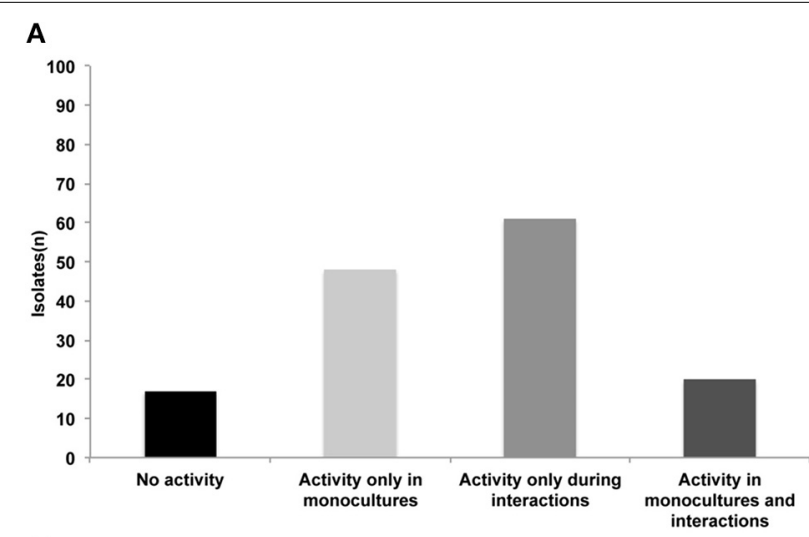

B

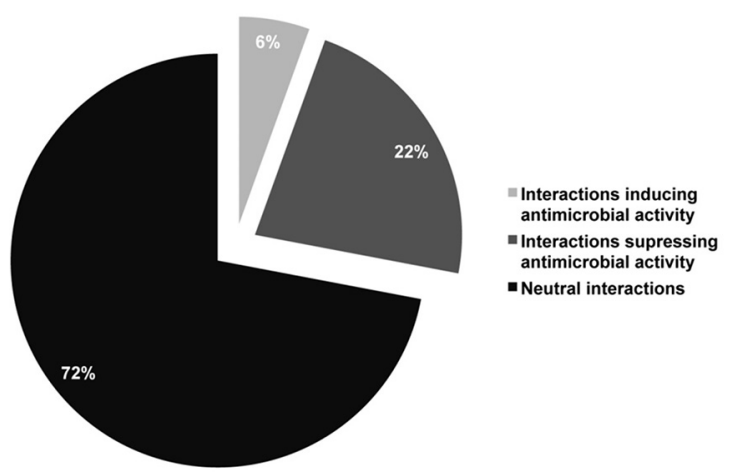

FIGURE 2 | (A) Number of bacterial isolates exhibiting different patterns of antimicrobial activity against E. coli WA321 and/or S. aureus 533R4; in total 146 bacterial isolates were studied (B) Frequencies of interactions (1) inducing antimicrobial activity, (2) suppressing antimicrobial activity and (3) neutral interactions (no induction/suppression). Number of tested combinations $(n=2798)$.

Table 1 | Frequencies of antimicrobial activity for the phyla included in this study.

\begin{tabular}{|c|c|c|c|c|c|}
\hline $\begin{array}{l}\text { Phylum/phylogenetic } \\
\text { class }\end{array}$ & $\begin{array}{c}\text { Total } \\
\text { abundance }\end{array}$ & $\begin{array}{l}\text { AM active vs. } E \text {. coli } \\
\text { in monoculture }\end{array}$ & $\begin{array}{c}\text { AM active vs. } E \text {. coli } \\
\text { in interaction }\end{array}$ & $\begin{array}{c}\text { AM active vs. } S \text {. aureus } \\
\text { in monoculture }\end{array}$ & $\begin{array}{c}\text { AM active vs. } S \text {. aureus } \\
\text { in interaction }\end{array}$ \\
\hline \multicolumn{6}{|l|}{ Actinobacteria } \\
\hline Actinobacteria & 11 & 3 & 3 & 4 & 5 \\
\hline \multicolumn{6}{|l|}{ Bacteroidetes } \\
\hline Flavobacteria & 19 & 1 & 3 & 3 & 11 \\
\hline Sphingobacteria & 1 & & 1 & & \\
\hline \multicolumn{6}{|l|}{ Firmicutes } \\
\hline Bacilli & 7 & 2 & 2 & 3 & 2 \\
\hline \multicolumn{6}{|l|}{ Proteobacteria } \\
\hline a-proteobacteria & 14 & & 1 & 3 & 9 \\
\hline$\beta$-proteobacteria & 65 & 17 & 8 & 26 & 25 \\
\hline$\gamma$-proteobacteria & 29 & 2 & 2 & 12 & 7 \\
\hline$(n)$ isolates & 146 & 25 & 20 & 51 & 59 \\
\hline
\end{tabular}




\section{ANTIMICROBIAL ACTIVITY DURING INTERACTIONS}

\section{Interaction-mediated activity against $E$. coli WA321}

Growth of E. coli WA321 was inhibited by 14 pair-wise combinations involving 20 isolates that did not show antimicrobial activity in monoculture (Table 2). Some isolates were present in different combinations. For example, Janthinobacterium sp. AD80 and Streptomyces sp. AD108 were present in 4 combinations with induced activity (Table 2). Combinations inhibiting growth of E. coli WA321 consisted of Gram-negative/Gram-positive isolates (7 interactions) or Gram-negative/Gram-negative (6 interactions). Only in one case, a combination of two Gram-positive isolates

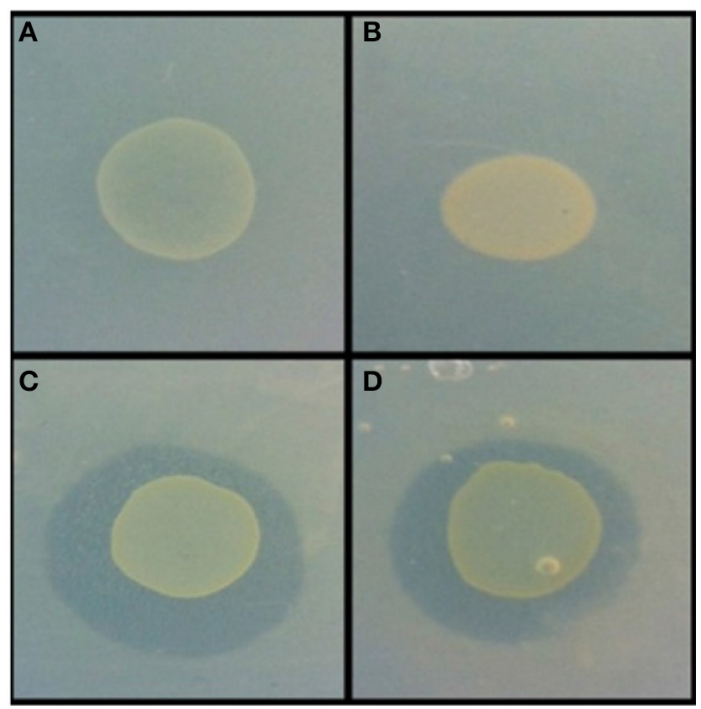

FIGURE 3 | Example of antimicrobial activity revealed via the agar overlay assay. Burkholderia sp. AD24 monoculture (A), Paenibacillus sp. AD83 monoculture (B), Interaction Burkholderia sp. AD24 with Paenibacillus sp. AD83 antimicrobial activity against S. aureus 533R4 (C) and antimicrobial activity against E. coli WA321 (D).
(Micrococcus and Microbacterium) showed activity against E. coli.

\section{Interaction-mediated activity against $S$. aureus 533R4}

Growth of S. aureus 533R4 was inhibited by 63 pair-wise combinations involving 59 isolates. Several isolates were present in multiple combinations that inhibited growth of S. aureus (Table 3 ). Burkholderia sp. AD37, Collimonas sp. AD65, Collimonas sp. AD98, Janthinobacterium sp. AD72, Micrococcus sp. AD31, Pseudomonas sp. AD104, Streptomyces spp. AD92 and AD108, Variovorax sp. AD143 were all involved in more than five combinations that inhibited the growth of $S$. aureus. Most of the combinations consisted of Gram-negative/Gram-negative isolates (35 interactions) or Gram-negative/Gram-positive isolates (25 interactions). Activity against $S$. aureus was only observed 3 times for Gram-positive/Gram-positive combinations (Figure S2).

\section{Interaction-mediated activity against both target organisms}

Nine isolates were present in pair-wise combinations that exhibited antimicrobial activity against both target organisms (Table S1). Two combinations were inhibitory for both target organisms. These were the combinations of Burkholderia sp. AD24 and Paenibacillus sp. AD83 (Figure 3) and of Streptomyces sp. AD108 and Burkholderia sp. AD37.

\section{Interactions inducing antimicrobial activity against $E$. coli or S. aureus}

The number of pair-wise combinations with induced antimicrobial activity against $S$. aureus 533R4 was higher than against E. coli WA321. Most combinations with induced activity against E. coli WA321 involved beta-Proteobacteria, Actinobacteria, Flavobacteria, and Bacilli (Figure 4A). Combinations with induced activity against $S$. aureus 533R4 involved all classes of Proteobacteria, Actinobacteria, Flavobacteria, and Bacilli (Figure 4B). Two phylogenetic classes, Flavobacteria and alphaProteobacteria, were 3 times more represented in pair-wise combinations with antimicrobial activity than in monocultures (Table 1).

Table 2 | Bacterial pairs with induced antimicrobial activity against $E$. coli WA 321.

\begin{tabular}{|c|c|c|c|}
\hline Phylogenetic class & Genus A & Phylogenetic class & Genus B \\
\hline alpha-proteobacteria & Phyllobacterium sp. AD152 & gamma-proteobacteria & Pseudomonas sp. AD114 \\
\hline beta-proteobacteria & Burkholderia sp. AD24 & beta-proteobacteria & Collimonas sp. AD68 \\
\hline beta-proteobacteria & Burkholderia sp. AD32 & beta-proteobacteria & Janthinobacterium sp. AD80 \\
\hline beta-proteobacteria & Janthinobacterium sp. AD72 & Flavobacteria & Flavobacterium sp. AD151 \\
\hline beta-proteobacteria & Janthinobacterium sp. AD80 & gamma-proteobacteria & Dyella sp. AD56 \\
\hline beta-proteobacteria & Janthinobacterium sp. AD80 & beta-proteobacteria & Variovorax sp. AD133 \\
\hline Actinobacteria & Streptomyces sp. AD108 & beta-proteobacteria & Burkholderia sp. AD37 \\
\hline Actinobacteria & Streptomyces sp. AD108 & Flavobacteria & Flavobacterium sp. AD47 \\
\hline Actinobacteria & Streptomyces sp. AD108 & Flavobacteria & Flavobacterium sp. AD84 \\
\hline Actinobacteria & Streptomyces sp. AD108 & Sphingobacteria & Pedobacter sp. V48 \\
\hline Actinobacteria & Microbacterium sp. AD141 & beta-proteobacteria & Janthinobacterium sp. AD80 \\
\hline Bacilli & Bacillus sp. AD78 & beta-proteobacteria & Burkholderia sp. AD11 \\
\hline Bacilli & Paenibacillus sp. AD83 & beta-proteobacteria & Burkholderia sp. AD24 \\
\hline Actinobacteria & Micrococcus sp. AD31 & Actinobacteria & Microbacterium sp. AD141 \\
\hline
\end{tabular}


Table 3 | Bacterial pairs with induced antimicrobial activity against $S$. aureus 533R4.

\begin{tabular}{|c|c|c|c|}
\hline Phylogenetic class & Genus A & Phylogenetic class & Genus B \\
\hline alpha-proteobacteria & Phyllobacterium sp. AD153 & beta-proteobacteria & Collimonas sp. AD65 \\
\hline beta-proteobacteria & Janthinobacterium sp. AD72 & gamma-proteobacteria & Dyella sp. AD46 \\
\hline beta-proteobacteria & Janthinobacterium sp. AD72 & beta-proteobacteria & Collimonas sp. AD97 \\
\hline beta-proteobacteria & Collimonas sp. AD67 & beta-proteobacteria & Collimonas sp. AD68 \\
\hline beta-proteobacteria & Janthinobacterium sp. AD75 & beta-proteobacteria & Burkholderia sp. AD37 \\
\hline beta-proteobacteria & Collimonas sp. AD69 & Flavobacteria & Flavobacterium sp. AD146 \\
\hline beta-proteobacteria & Collimonas sp. AD71 & alpha-proteobacteria & Rhizobium sp. AD148 \\
\hline beta-proteobacteria & Collimonas sp. AD88 & beta-proteobacteria & Burkholderia sp. AD37 \\
\hline beta-proteobacteria & Collimonas sp. AD89 & alpha-proteobacteria & Mesorhizobium sp. AD38 \\
\hline beta-proteobacteria & Variovorax sp. AD143 & beta-proteobacteria & Collimonas sp. AD65 \\
\hline beta-proteobacteria & Variovorax sp. AD143 & alpha-proteobacteria & Mesorhizobium sp. AD112 \\
\hline beta-proteobacteria & Variovorax sp. AD143 & alpha-proteobacteria & Phyllobacterium sp. AD153 \\
\hline beta-proteobacteria & Collimonas sp. AD98 & alpha-proteobacteria & Phyllobacterium sp. AD159 \\
\hline beta-proteobacteria & Collimonas sp. AD98 & gamma-proteobacteria & Pseudomonas sp. AD105 \\
\hline beta-proteobacteria & Collimonas sp. AD137 & gamma-proteobacteria & Pseudomonas sp. AD157 \\
\hline beta-proteobacteria & Collimonas sp. AD97 & beta-proteobacteria & Collimonas sp. AD62 \\
\hline beta-proteobacteria & Roseateles sp. AD145 & beta-proteobacteria & Collimonas sp. AD67 \\
\hline gamma-proteobacteria & Pseudomonas sp. AD124 & beta-proteobacteria & Collimonas sp. AD65 \\
\hline Flavobacteria & Flavobacterium sp. AD155 & beta-proteobacteria & Collimonas sp. AD98 \\
\hline Flavobacteria & Flavobacterium sp. AD44 & beta-proteobacteria & Collimonas sp. AD62 \\
\hline Actinobacteria & Micrococcus sp. AD31 & beta-proteobacteria & Collimonas sp. AD65 \\
\hline Actinobacteria & Micrococcus sp. AD31 & beta-proteobacteria & Collimonas sp. AD69 \\
\hline Actinobacteria & Micrococcus sp. AD31 & beta-proteobacteria & Collimonas sp. AD70 \\
\hline Actinobacteria & Micrococcus sp. AD31 & Flavobacteria & Flavobacterium sp. AD85 \\
\hline Actinobacteria & Micrococcus sp. AD31 & beta-proteobacteria & Collimonas sp. AD88 \\
\hline Actinobacteria & Micrococcus sp. AD31 & alpha-proteobacteria & Phyllobacterium sp. AD136 \\
\hline Actinobacteria & Micrococcus sp. AD31 & gamma-proteobacteria & Stenotrophomonas sp. AD147 \\
\hline Actinobacteria & Micrococcus sp. AD31 & Flavobacteria & Flavobacterium sp. AD156 \\
\hline Actinobacteria & Streptomyces sp. AD92 & beta-proteobacteria & Collimonas sp. AD65 \\
\hline Actinobacteria & Streptomyces sp. AD92 & beta-proteobacteria & Variovorax sp. AD143 \\
\hline Actinobacteria & Streptomyces sp. AD92 & beta-proteobacteria & Burkholderia sp. AD18 \\
\hline Actinobacteria & Streptomyces sp. AD92 & alpha-proteobacteria & Phyllobacterium sp. AD153 \\
\hline Actinobacteria & Tsukamurella sp. AD106 & beta-proteobacteria & Collimonas sp. AD89 \\
\hline Actinobacteria & Tsukamurella sp. AD106 & Flavobacteria & Chryseobacterium sp. AD48 \\
\hline Actinobacteria & Streptomyces sp. AD108 & beta-proteobacteria & Burkholderia sp. AD37 \\
\hline Actinobacteria & Streptomyces sp. AD108 & Flavobacteria & Chryseobacterium sp. AD48 \\
\hline Actinobacteria & Streptomyces sp. AD108 & beta-proteobacteria & Janthinobacterium sp. AD73 \\
\hline
\end{tabular}


Table 3 | Continued

\begin{tabular}{llll}
\hline Phylogenetic class & Genus A & Phylogenetic class & Genus B \\
\hline Actinobacteria & Streptomyces sp. AD108 & beta-proteobacteria & Janthinobacterium sp. AD75 \\
Actinobacteria & Streptomyces sp. AD108 & beta-proteobacteria & Collimonas sp. AD88 \\
Actinobacteria & Streptomyces sp. AD108 & beta-proteobacteria & Collimonas sp. AD101 \\
Actinobacteria & Streptomyces sp. AD108 & gamma-proteobacteria & Pseudomonas sp. AD104 \\
Actinobacteria & Microbacterium sp. AD141 & beta-proteobacteria & Burkholderia sp. AD37 \\
Bacilli & Paenibacillus sp. AD83 & beta-proteobacteria & Collimonas sp. AD62 \\
Bacilli & Paenibacillus sp. AD83 & beta-proteobacteria & Burkholderia sp. AD24 \\
Bacilli & Paenibacillus sp. AD116 & gamma-proteobacteria & Pseudomonas sp. AD104 \\
Actinobacteria & Micrococcus sp. AD31 & Actinobacteria & Tsukamurella sp. AD106 \\
Actinobacteria & Tsukamurella sp. AD106 & Actinobacteria & Microbacterium sp. AD141 \\
Actinobacteria & Streptomyces sp. AD108 & Actinobacteria & Microbacterium sp. AD141 \\
\hline
\end{tabular}

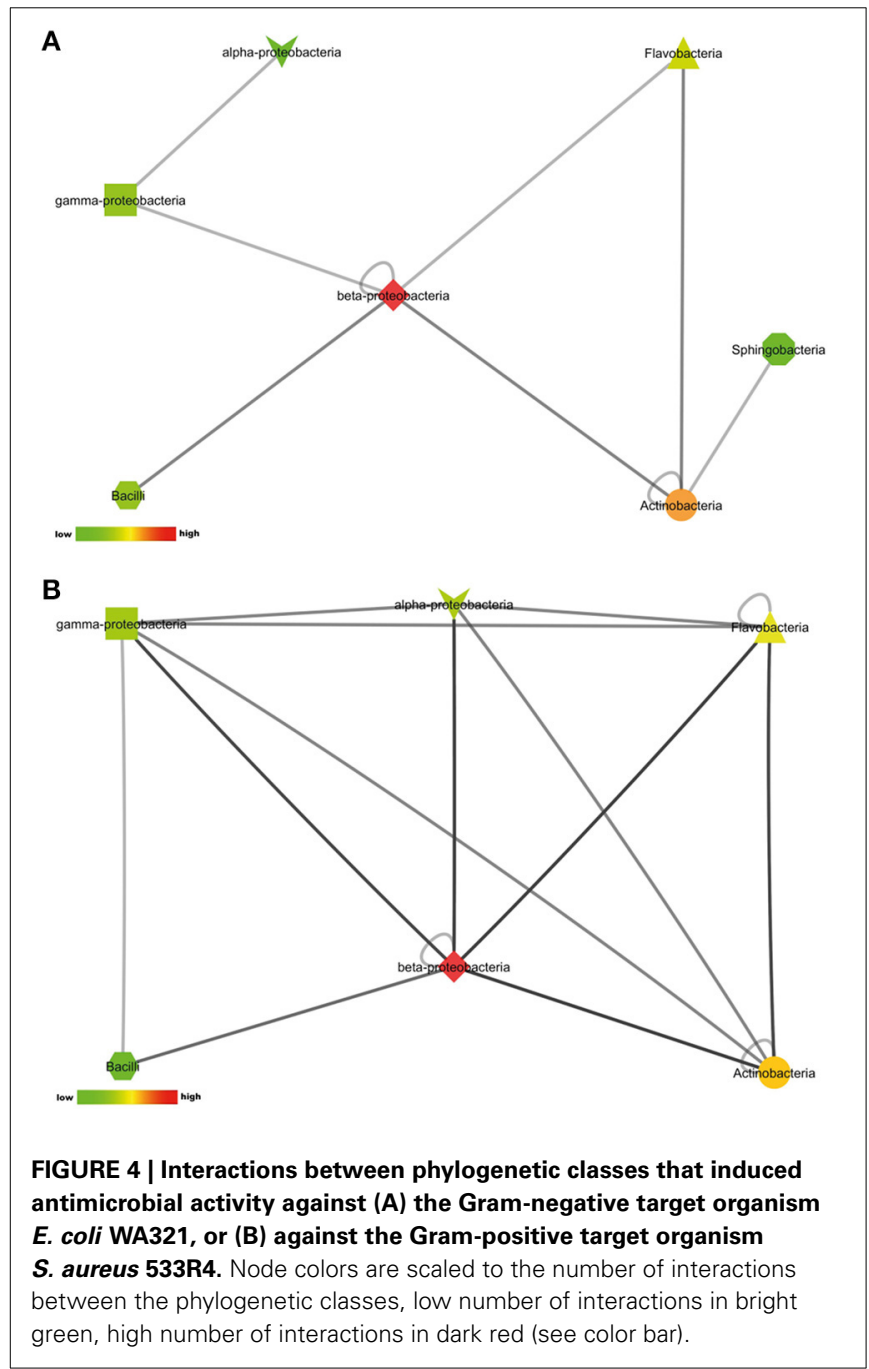

Interactions suppressing antimicrobial activity against $E$. coli or S. aureus

$22 \%$ of the isolates with antimicrobial activity in monoculture lost this activity during interactions. This apparent suppression of antimicrobial activity was found among all bacterial classes

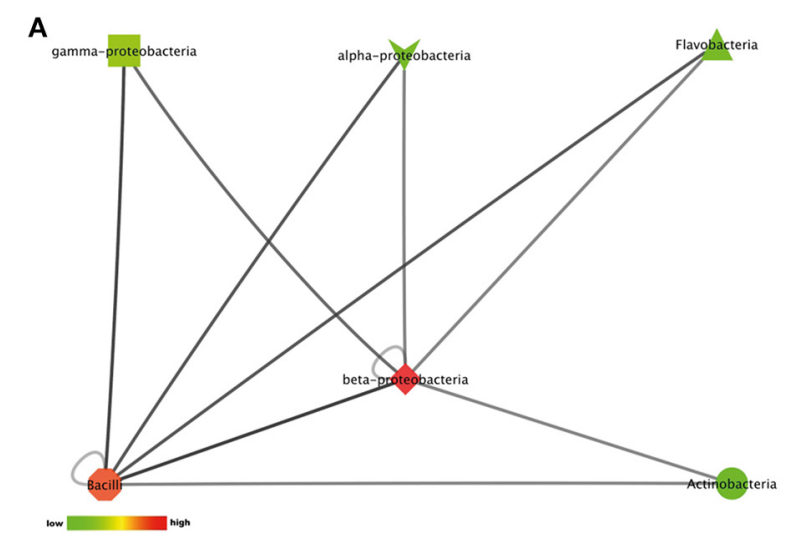

B

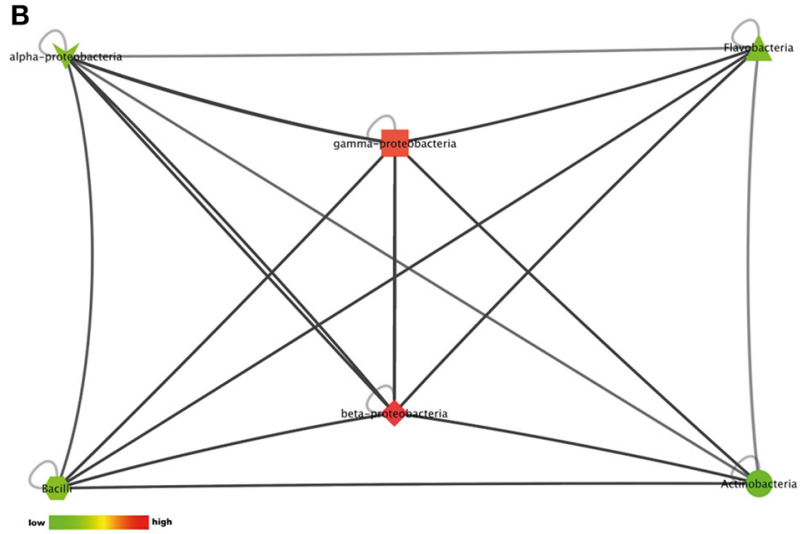

FIGURE 5 | Interactions between phylogenetic classes that inhibited antimicrobial activity against (A) the Gram-negative target organism E. coli WA321, or (B) against the Gram-positive target organism S. aureus 533R4. Node colors are scaled to the respective number of interactions between the phylogenetic classes (low number of interactions in bright colors, high number of interactions in dark colors). 


\section{DISCUSSION}

Recent studies indicated the importance of interspecific bacterial interactions for triggering antibiotic production (Garbeva et al., 2011a; Seyedsayamdost et al., 2012). However, the frequency of such events in natural bacterial communities is not known. Our study focused on a collection of bacterial isolates from similar soil habitats, i.e., sandy soils covered by vegetation patches consisting of sand sedge ( $C$. arenaria). Hence, the chance that actual interactions between these bacteria can occur in their natural habitat seems plausible. Induction of antibiotic production in pair-wise combinations was not found to be an abundant phenomenon as it occurred in $\sim 6 \%$ of all interactions studied. Yet, $42 \%$ of the bacterial isolates were present in combinations that showed activity against at least one of the target organisms, whereas they did not show activity in monocultures. This seems to indicate that the composition of the interacting pairs is an important factor in the induction of antibiotic production.

The observed frequency of interaction-mediated induction of antibiotic production exemplifies that a high-throughput screening as the one developed here can be an important strategy for the discovery of novel cryptic antibiotics. Many pair-wise combinations have to be screened and, subsequently, interesting pairs can be studied in more detail with respect to elucidate the mechanisms underlying the induction, signals and genes involved in the production of the antibiotic compounds (Garbeva et al., 2011a; Traxler et al., 2013). Interactions that induced antimicrobial activity often involved combinations of phylogenetically different bacteria or interactions among betaProteobacteria and among Actinobacteria. The present work included several bacterial genera (e.g., Streptomyces, Burkholderia, Janthinobacterium and Paenibacillus) for which multiple antibiotics have been described previously (Pantanella et al., 2007; Berdy, 2012; Cornforth and Foster, 2013; Debois et al., 2013; Zhu, 2014). Hence, there is the possibility that our screening method will reveal bacteria that produce known antibiotics but only during co-cultivation.

Few bacterial isolates of the classes Flavobacteria and alphaProteobacteria showed antimicrobial activity in monoculture, whereas several strains were present in antibiotic producing combinations. Hence, for these groups there is a clear potential to discover novel antibiotics. Of the 146 tested isolates, 33\% showed antimicrobial activity in monoculture. This obtained frequency is in line with previous studies on frequencies of antimicrobial activity in Streptomyces spp. (Davelos et al., 2004; Kinkel et al., 2014). However, in many cases antibiotic production was lost when the strain was combined with another strain and only a small percentage (13\%) kept their antimicrobial activity in both combinations and monoculture. This suppressing effect on antibiotic production was more often found $(22 \%$ of all combinations) than the induction of antibiotic production ( $\sim 6 \%$ of all combinations). Several mechanisms can be responsible for the observed suppression of antimicrobial activity during interactions e.g., interference with the quorum sensing system or other signal transduction pathways involved in regulating antibiotic production (Gonzalez and Keshavan, 2006; Venturi and Subramoni, 2009; Christensen et al., 2013) or direct growth inhibition of the antibiotic producing strain (Straight et al., 2007; Hibbing et al., 2010; Schneider et al., 2012). Another possible reason for the observed inhibition of antimicrobial activity during interactions could be lower nutrient availability for each strain during co-cultivation. Growth conditions and nutrient availability are important factors affecting the production of antimicrobial compounds in bacteria (van Wezel and McDowall, 2011). Antibiotic resistance mechanisms might also play a role in the observed inhibition of antimicrobial activity during co-cultivation (Rice, 2006; Wellington et al., 2013).

Depending on the target organism there was a clear difference in antimicrobial activity with higher activity against the Gram-positive than against the Gram-negative organism (in both monocultures and interactions), which is in line with previous reports that Gram-positive bacteria are generally more sensitive to antibiotics (Rice, 2006; Giske et al., 2008; Zhu, 2014).

Soil and rhizosphere are environments where bacteria evolved the ability to produce antibiotics as competitive tool for their survival (Hibbing et al., 2010). Root-associated bacteria with antimicrobial potential play an important role in plant health (Raaijmakers and Mazzola, 2012) and understanding microbial interactions affecting antimicrobial activity may be helpful in understanding the functions and mechanisms of microbial communities contributing to plant protection. The knowledge obtained here could help in selecting the right players in microbial consortia and as suggested by Mendes (Mendes et al., 2013) to design "a minimal microbiome" that comprises a set of microorganisms needed to fulfill a specific ecosystem services like e.g., disease suppression.

In conclusion, the high-throughput screening method developed in this work allows for a fast detection of interactionmediated induction or suppression of antibiotic production in soil bacteria. Such screening also allows for a better insight into different interference competitive strategies that are operational in microbial communities. This knowledge in turn can be used for construction of synthetic microbial communities (Shong et al., 2012; De Roy et al., 2013; Grosskopf and Soyer, 2014).

\section{ACKNOWLEDGMENTS}

This work is supported by the BE-Basic Foundation. Paolina Garbeva is financed by The Netherlands Organization for Scientific Research (NWO) MEERVOUD personal grant (836.09.004). This is publication 5682 of the NIOO-KNAW.

\section{SUPPLEMENTARY MATERIAL}

The Supplementary Material for this article can be found online at: http://www.frontiersin.org/journal/10.3389/fmicb. 2014.00567/abstract

\section{REFERENCES}

Altschul, S. F., Madden, T. L., Schaffer, A. A., Zhang, J. H., Zhang, Z., Miller, W., et al. (1997). Gapped BLAST and PSI-BLAST: a new generation of protein database search programs. Nucleic Acids Res. 25, 3389-3402. doi: $10.1093 /$ nar/25.17.3389

Berdy, J. (2012). Thoughts and facts about antibiotics: where we are now and where we are heading. J. Antibiot. 65, 385-395. doi: 10.1038/ja.2012.27

Chiang, Y. M., Chang, S. L., Oakley, B. R., and Wang, C. C. C. (2011). Recent advances in awakening silent biosynthetic gene clusters and linking orphan clusters to natural products in microorganisms. Curr. Opin. Chem. Biol. 15, 137-143. doi: 10.1016/j.cbpa.2010.10.011 
Christensen, L. D., van Gennip, M., Rybtke, M. T., Wu, H., Chiang, W. C., Alhede, M., et al. (2013). Clearance of Pseudomonas aeruginosa foreign-body biofilm infections through reduction of the cyclic DiGMP level in bacteria. Infect. Immun. 81, 2705-2731. doi: 10.1128/IAI. 00332-13

Cornforth, D. M., and Foster, K. R. (2013). Competition sensing: the social side of bacterial stress responses. Nat. Rev. Microbiol. 11, 285-293. doi: 10.1038/nrmicro2977

Dantas, G., Sommer, M. O. A., Oluwasegun, R. D., and Church, G. M. (2008). Bacteria subsisting on antibiotics. Science 320, 100-103. doi: 10.1126/science. 1155157

Davelos, A. L., Kinkel, L. L., and Samac, D. A. (2004). Spatial variation in frequency and intensity of antibiotic interactions among Streptomycetes from prairie soil. Appl. Environ. Microbiol. 70, 1051-1058. doi: 10.1128/AEM.70.2.10511058.2004

D'costa, V. M., McGrann, K. M., Hughes, D. W., and Wright, G. D. (2006). Sampling the antibiotic resistome. Science 311, 374-377. doi: 10.1126/science. 1120800

De Boer, W., Wagenaar, A. M., Klein Gunnewiek, P. J. A., and van Veen, J. A. (2007b). In vitro suppression of fungi caused by combinations of apparently non-antagonistic soil bacteria. FEMS Microbiol. Ecol. 59, 177-185. doi: 10.1111/j.1574-6941.2006.00197.x

De Boer, W., Wagenaar, A. M., Klein Gunnewiek, P. J., and van Veen, J. A. (2007a). In vitro suppression of fungi caused by combinations of apparently non-antagonistic soil bacteria. FEMS Microbiol. Ecol. 59, 177-185. doi: 10.1111/j.1574-6941.2006.00197.x

Debois, D., Ongena, M., Cawoy, H., and De Pauw, E. (2013). MALDI-FTICR MS Imaging as a powerful tool to identify Paenibacillus antibiotics involved in the inhibition of plant pathogens. J. Am. Soc. Mass Spectrom. 24, 1202-1213. doi: 10.1007/s13361-013-0620-2

Demoling, F., Figueroa, D., and Baath, E. (2007). Comparison of factors limiting bacterial growth in different soils. Soil Biol. Biochem. 39, 2485-2495. doi: 10.1016/j.soilbio.2007.05.002

De Ridder-Duine, A. S., Kowalchuk, G. A., Klein Gunnewiek, P. J. A., Smant, W., van Veen, J. A., and De Boer, W. (2005). Rhizosphere bacterial community composition in natural stands of Carex arenaria (sand sedge) is determined by bulk soil community composition. Soil Biol. Biochem. 37, 349-357. doi: 10.1016/j.soilbio.2004.08.005

De Roy, K., Marzorati, M., Van den Abbeele, P., Van de Wiele, T., and Boon, N. (2013). Synthetic microbial ecosystems: an exciting tool to understand and apply microbial communities. Environ. Microbiol. 16, 1472-1481. doi: 10.1111/1462-2920.12343

Edwards, U., Rogall, T., Blocker, H., Emde, M., and Bottger, E. C. (1989). Isolation and direct complete nucleotide determination of entire genes - Characterization of a gene coding for 16s-ribosomal rna. Nucleic Acids Res. 17, 7843-7853. doi: 10.1093/nar/17.19.7843

Firn, R. D., and Jones, C. G. (2003). Natural products - a simle model to explain chemical diversity. Nat. Prod. Rep. 20, 382-391. doi: 10.1039/b208815k

Gans, J., Wolinsky, M., and Dunbar, J. (2005). Computational improvements reveal great bacterial diversity and high metal toxicity in soil. Science 309, 1387-1390. doi: 10.1126/science. 1112665

Garbeva, P., and De Boer, W. (2009). Inter-specific interactions between carbonlimited soil bacteria affect behavior and gene expression. Microb. Ecol. 58, 36-46. doi: 10.1007/s00248-009-9502-3

Garbeva, P., Silby, M. W., Raaijmakers, J. M., Levy, S. B., and Boer, W. (2011a). Transcriptional and antagonistic responses of Pseudomonas fluorescens Pf0-1 to phylogenetically different bacterial competitors. ISME J. 5, 973-985. doi: 10.1038/ismej.2010.196

Garbeva, P., Tyc, O., Remus-Emsermann, M. N. P., van der Wal, A., Vos, M., Silby, M., et al. (2011b). No apparent costs for facultative antibiotic production by the soil bacterium Pseudomonas fluorescens Pf0-1. PLoS ONE 6:e27266. doi: 10.1371/journal.pone.0027266

Giske, C. G., Monnet, D. L., Cars, O., and Carmeli, Y. (2008). Clinical and economic impact of common multidrug-resistant gram-negative bacilli. Antimicrob. Agents Chemother. 52, 813-821. doi: 10.1128/AAC.01169-07

Goh, E. B., Yim, G., Tsui, W., McClure, J., Surette, M. G., and Davies, J. (2002). Transcriptional modulation of bacterial gene expression by subinhibitory concentrations of antibiotics. Proc. Natl. Acad. Sci. U.S.A. 99, 17025-17030. doi: $10.1073 /$ pnas. 252607699
Gonzalez, J. E., and Keshavan, N. D. (2006). Messing with bacterial quorum sensing. Microbiol. Mol. Biol. Rev. 70, 859-875. doi: 10.1128/MMBR.00002-06

Grosskopf, T., and Soyer, O. S. (2014). Synthetic microbial communities. Curr. Opin. Microbiol. 18, 72-77. doi: 10.1016/j.mib.2014.02.002

Hibbing, M. E., Fuqua, C., Parsek, M. R., and Peterson, S. B. (2010). Bacterial competition: surviving and thriving in the microbial jungle. Nat. Rev. Microbiol. 8, 15-25. doi: 10.1038/nrmicro2259

Ikeda, H., Ishikawa, J., Hanamoto, A., Shinose, M., Kikuchi, H., Shiba, T., et al. (2003). Complete genome sequence and comparative analysis of the industrial microorganism Streptomyces avermitilis. Nat. Biotechnol. 21, 526-531. doi: $10.1038 /$ nbt820

Kinkel, L. L., Schlatter, D. C., Xiao, K., and Baines, A. D. (2014). Sympatric inhibition and niche differentiation suggest alternative coevolutionary trajectories among Streptomycetes. Isme J. 8, 249-256. doi: 10.1038/ismej.2013.175

Lane, D. J. (1991). "16S/23S rRNA sequencing," in Nucleic Acid Techniques in Bacterial Systematics, eds E. Stackebrandt and M. Goodfellow (New York, NY: John Wiley and Sons), 15-175.

Linares, J. F., Gustafsson, I., Baquero, F., and Martinez, J. L. (2006). Antibiotics as intermicrobial signaling agents instead of weapons. Proc. Natl. Acad. Sci. U.S.A. 103, 19484-19489. doi: 10.1073/pnas.0608949103

Lyon, G. J., and Muir, T. W. (2003). Chemical signaling among bacteria and its inhibition. Chem. Biol. 10, 1007-1021. doi: 10.1016/j.chembiol.2003.11.003

Maurhofer, M., Baehler, E., Notz, R., Martinez, V., and Keel, C. (2004). Cross talk between 2,4-diacetylphloroglucinol-producing biocontrol pseudomonads on wheat roots. Appl. Environ. Microbiol. 70, 1990-1998. doi: 10.1128/AEM.70.4.1990-1998.2004

Mendes, R., Garbeva, P., and Raaijmakers, J. M. (2013). The rhizosphere microbiome: significance of plant beneficial, plant pathogenic, and human pathogenic microorganisms. FEMS Microbiol. Rev. 37, 634-663. doi: 10.1111/15746976.12028

Nkanga, E. J., and Hagedorn, C. (1978). Detection of antibiotic-producing Streptomyces inhabiting forest soils. Antimicrob. Agents Chemother. 14, 51-59. doi: 10.1128/AAC.14.1.51

Pantanella, F., Berlutti, F., Passariello, C., Sarli, S., Morea, C., and Schippa, S. (2007). Violacein and biofilm production in Janthinobacterium lividum. J. Appl. Microbiol. 102, 992-999. doi: 10.1111/j.1365-2672.2006.03155.x

Raaijmakers, J. M., and Mazzola, M. (2012). Diversity and natural functions of antibiotics produced by beneficial and plant pathogenic bacteria. Annu. Rev. Phytopathol. 50, 403-424. doi: 10.1146/annurev-phyto-081211172908

Rice, L. B. (2006). Antimicrobial resistance in gram-positive bacteria. Am. J. Infect. Control 34, S11-S19, discussion; S64-S73. doi: 10.1016/j.ajic.2006.05.220

Romero, D., Traxler, M. F., Lopez, D., and Kolter, R. (2011). Antibiotics as signal molecules. Chem. Rev. 111, 5492-5505. doi: 10.1021/cr2000509

Rousk, J., and Baath, E. (2007). Fungal and bacterial growth in soil with plant materials of different C/N ratios. FEMS Microbiol. Ecol. 62, 258-267. doi: 10.1111/j.1574-6941.2007.00398.x

Rousk, J., Demoling, L. A., and Baath, E. (2009). Contrasting short-term antibiotic effects on respiration and bacterial growth compromises the validity of the selective respiratory inhibition technique to distinguish fungi and bacteria. Microb. Ecol. 58, 75-85. doi: 10.1007/s00248-008-9444-1

Saleh, O., Bonitz, T., Flinspach, K., Kulik, A., Burkard, N., Muhlenweg, A., et al. (2012). Activation of a silent phenazine biosynthetic gene cluster reveals a novel natural product and a new resistance mechanism against phenazines. Medchemcomm 3, 1009-1019. doi: 10.1039/c2md20045g

Sambrook, J., and Russell, D. W. (2001). Molecular Cloning: A Laboratory Manual. $3 r d E d n$. Plainview, NY: Cold Spring Harbor Laboratory Press.

Scherlach, K., and Hertweck, C. (2009). Triggering cryptic natural product biosynthesis in microorganisms. Org. Biomol. Chem. 7, 1753-1760. doi: $10.1039 / \mathrm{b} 821578 \mathrm{~b}$

Schneider, J., Yepes, A., Garcia-Betancur, J. C., Westedt, I., Mielich, B., and Lopez, D. (2012). Streptomycin-induced expression in Bacillus subtilis of YtnP, a lactonase-homologous protein that inhibits development and streptomycin production in Streptomyces griseus. Appl. Environ. Microbiol. 78, 599-603. doi: 10.1128/AEM.06992-11

Seyedsayamdost, M. R., Traxler, M. F., Clardy, J., and Kolter, R. (2012). Old meets new: using interspecies interactions to detect secondary metabolite production in actinomycetes. Methods Enzymol. 517, 89-109. doi: 10.1016/B978-0-12404634-4.00005-X 
Shannon, P., Markiel, A., Ozier, O., Baliga, N. S., Wang, J. T., Ramage, D., et al. (2003). Cytoscape: a software environment for integrated models of biomolecular interaction networks. Genome Res. 13, 2498-2504. doi: 10.1101/gr. 1239303

Shong, J., Jimenez Diaz, M. R., and Collins, C. H. (2012). Towards synthetic microbial consortia for bioprocessing. Curr. Opin. Biotechnol. 23, 798-802. doi: 10.1016/j.copbio.2012.02.001

Slattery, M., Rajbhandari, I., and Wesson, K. (2001). Competition-mediated antibiotic induction in the marine bacterium Streptomyces tenjimariensis. Microb. Ecol. 41, 90-96. doi: 10.1007/s002480000084

Straight, P. D., Fischbach, M. A., Walsh, C. T., Rudner, D. Z., and Kolter, R. (2007). A singular enzymatic megacomplex from Bacillus subtilis. Proc. Natl. Acad. Sci. U.S.A. 104, 305-310. doi: 10.1073/pnas.0609073103

Strickland, M. S., Lauber, C., Fierer, N., and Bradford, M. A. (2009). Testing the functional significance of microbial community composition. Ecology 90, 441-451. doi: 10.1890/08-0296.1

Traxler, M. F., Watrous, J. D., Alexandrov, T., Dorrestein, P. C., and Kolter, R. (2013). Interspecies interactions stimulate diversification of the Streptomyces coelicolor secreted metabolome. MBio 4:e00459-13. doi: 10.1128/mBio.00459-13

Uroz, S., Buee, M., Murat, C., Frey-Klett, P., and Martin, F. (2010). Pyrosequencing reveals a contrasted bacterial diversity between oak rhizosphere and surrounding soil. Environ. Microbiol. Rep. 2, 281-288. doi: 10.1111/j.17582229.2009.00117.x

van Wezel, G. P., and McDowall, K. J. (2011). The regulation of the secondary metabolism of Streptomyces: new links and experimental advances. Nat. Prod. Rep. 28, 1311-1333. doi: 10.1039/clnp00003a

Venturi, V., and Subramoni, S. (2009). Future research trends in the major chemical language of bacteria. HFSP J. 3, 105-116. doi: 10.2976/1.3065673
Wellington, E. M., Boxall, A. B., Cross, P., Feil, E. J., Gaze, W. H., Hawkey, P. M., et al. (2013). The role of the natural environment in the emergence of antibiotic resistance in gram-negative bacteria. Lancet Infect. Dis. 13, 155-165. doi: 10.1016/S1473-3099(12)70317-1

Yin, B., Crowley, D., Sparovek, G., De Melo, W. J., and Borneman, J. (2000). Bacterial functional redundancy along a soil reclamation gradient. Appl. Environ. Microbiol. 66, 4361-4365. doi: 10.1128/AEM.66.10.4361-4365.2000

Zhu, H. (2014). Environmental and Metabolomic Study of Antibiotic Production by Actinomycetes. Ph.D. Thesis, Leiden University, The Netherlands.

Conflict of Interest Statement: The authors declare that the research was conducted in the absence of any commercial or financial relationships that could be construed as a potential conflict of interest.

Received: 19 August 2014; accepted: 08 October 2014; published online: 28 October 2014.

Citation: Tyc O, van den Berg M, Gerards S, van Veen JA, Raaijmakers JM, de Boer $W$ and Garbeva $P$ (2014) Impact of interspecific interactions on antimicrobial activity among soil bacteria. Front. Microbiol. 5:567. doi: 10.3389/fmicb.2014.00567

This article was submitted to Terrestrial Microbiology, a section of the journal Frontiers in Microbiology.

Copyright (C) 2014 Tyc, van den Berg, Gerards, van Veen, Raaijmakers, de Boer and Garbeva. This is an open-access article distributed under the terms of the Creative Commons Attribution License (CC BY). The use, distribution or reproduction in other forums is permitted, provided the original author(s) or licensor are credited and that the original publication in this journal is cited, in accordance with accepted academic practice. No use, distribution or reproduction is permitted which does not comply with these terms. 